\title{
EL CUERPO DE LA REPÚBLICA. LA METÁFORA ORGANICISTA EN TRES DISCURSOS MÉDICOS DEL SIGLO DE ORO ESPAÑOL
}

\author{
Miguel Vicente Pedraz \\ Universidad de León \\ mvicp@unileon.es
}

\begin{abstract}
RESUMEN: Este artículo describe, analiza y compara la presencia de la metáfora del cuerpo en las obras de Bernardino Montaña, Jerónimo Merola y Cristóbal Pérez de Herrera. Considerando las constantes históricas en el uso metafórico del cuerpo como dispositivo de legitimación del poder, se estudia la pluralidad de significados políticos y económicos que se encuentran en los discursos de estos tres representativos médicos de corte del Siglo de Oro. El cotejo de los mismos, en el contexto inmediato de cada uno de ellos, ha permitido identificar los elementos de cambio formal, conceptual y práctico de la metáfora a lo largo de los casi sesenta años, y los dos relevos en la monarquía española, que median entre ellos.
\end{abstract}

Palabras clave: Metáfora corporal, Siglo de Oro, pensamiento político, Bernardino Montaña, Jerónimo Merola, Cristóbal Pérez de Herrera.

\section{THE BODY OF THE REPUBLIC. THE ORGANICIST METAPHOR IN THREE MEDICAL DISCOURSES OF THE SPANISH GOLDEN AGE}

\begin{abstract}
This article describes, analyzes and compares the presence of the body metaphor in the works of Bernardino Montaña, Jerónimo Merola and Christobal Pérez de Herrera. Considering the historical constants in the use of the body metaphor as mechanism of legitimation of power, the plurality of political and economic meanings found in the discourses of these three representatives court physicians of Spanish Renaissance, is studied. By documentary comparison, in the inmediat context, have been identified elements of formal, conceptual and practical change of metaphor along the nearly sixty years, and the two changes in the Spanish monarchy, which mediate between them.
\end{abstract}


Keywords: Bodily metaphor, Spanish Golden Age, Bernardino Montaña, Jerónimo Merola, Cristóbal Pérez de Herrera.

Recibido: 24 Marzo de 2016

Aceptado: 18 Mayo de 2016

\section{Introducción}

La morfología, la composición y la dinámica vital del cuerpo humano han sido desde muy antiguo fuente de inspiración en los más diversos ámbitos del pensamiento. Si bien la representación del cuerpo sensual y festivo, a menudo encarnados en el grotesco -en tanto que oposición al canon y con él al orden establecido ${ }^{1-}$, ha sido una constante incluso en la imaginería más académica, en la cultura occidental es notorio el predominio de la imagen del cuerpo como representación del orden. Innumerables analogías teológicas, cosmológicas, políticas o morales, entre otras, han ido configurando un nutrido campo simbólico que históricamente ha obrado como una llamada al conformismo social y, en todo caso, como mecanismo de legitimación de las relaciones de poder ${ }^{2}$.

Aunque con contenido ideológico diverso, de acuerdo con cada contexto y época, una de las simbologías somáticas más frecuentes es la denominada metáfora organicista: un recurso figurativo aplicado a la comprensión del orden político (de una congregación, de la ciudad, del estado, etc.) y, a la vez, a la naturalización de las diferencias entre sus miembros. Según dicha simbología -que se remonta a la Antigüedad clásica y en occidente se revitaliza en el siglo XII cuando Juan Salisbury la emplea en el Policaticus- todos los integrantes de una comunidad debían

1. BAJTIN, M., La cultura popular en la Edad Media y en el Renacimiento. Madrid 1989, pp. 2930.

2. Entre muchos otros estudios que han señalado y analizado el uso legitimador de la figura y composición corporal desde la Antigüedad, se pueden destacar los de LUBAC, H. Corpus Mysticum. L'Eucaristie et Eglise au Moyen Age. París 1949; MARAVALL, J.A. Estudios de historia del pensamiento español. Madrid 1983; LE GOFF, J. “¿La cabeza o el corazón? El uso político de las metáforas corporales durante la Edad Media". Feher, R. Nadaff y N. Tazi. Fragmentos para una historia del cuerpo humano III. Madrid 1992, pp.12 28; BARONA, J.L. El cuerpo alegórico: claves renacentistas para una interpretación de la naturaleza humana", Medicina e historia 47 (1993), pp. 7 28; VICENTE, M. "La Representación del cuerpo en la corte imaginada de Alfonso X El Sabio. Educación corporal y legitimación de la excelencia en la Segunda Partida" Bulletin of Hispanic Studies 80.1 (2003), pp. 21 40; RODRIGO, L. y VAL, P. Miradas desde la historia: el cuerpo y lo corporal en la sociedad medieval. M. Gil y J. Cáceres, J. Cuerpos que hablan. Barcelona 2008; DíEZ, B. "El cuerpo del poder: tacitismo y metáfora corporal en la obra de Suá rez de Figueroa". A. Baraibar y M. Insúa. El universo simbólico del poder en el Siglo de Oro, Nueva York/Pamplona 2012, pp. 7786. 
colaborar de forma solidaria al bien común mediante el ordenado cumplimiento de sus respectivos cometidos: de la misma manera que en el cuerpo humano se reúnen armónicamente todos sus miembros y órganos, cada individuo estaría llamado a contribuir, de acuerdo con su naturaleza o estatus, a la conservación del equilibrio social.

En la literatura hispánica hay ejemplos de este uso metafórico del cuerpo desde muy temprano aunque se presenta de forma regular, sobre todo, a partir del siglo XIV cuando el régimen feudal empieza a ceder en favor del régimen corporativo de base territorial, según ha puesto de relieve Maravall³. Los afanes centralizadores de la corona de Castilla encontrarían en la simbología organicista un excelente instrumento ideológico contra la resistencia de los reinos 'periféricos' a ser asimilados (in-corporados) y, también, contra de las fuerzas centrífugas de disgregación de los aún poderosos señores feudales. La metáfora llegaría en esta época a constituirse en un tópico que, de acuerdo con Delpech ${ }^{4}$, daría lugar a algunos de los más perfectos ejemplos europeos de la imaginería organicista.

A partir del siglo $\mathrm{XV}$, las versiones de la metáfora se verían multiplicadas; unas veces reproducidas, otras adaptadas y, en no pocas ocasiones, vulgarizadas en sus intenciones. De entre las más genuinas y fecundas destacan, ya en los siglos XVI y XVII, aquellas cuyos autores la aplicaron a la representación de la ciudad y de la República bajo una perspectiva médica. Es decir, construidas sobre los términos contrapuestos de salud y enfermedad en tanto que referentes del orden y el desorden social -prosperidad y quebranto económico, respectivamente-, los cuales resultaban especialmente propicios para las inquietudes de tantos médicos que, durante el Siglo de Oro -en algunos aspectos utopista y reformador-, consagraron su saber a la política social o económica. De entre los más insignes médicos 'ideólogos' de la época que empelaron la metáfora organicista en el contexto español figuran autores como Luis Lobera de Ávila, Andrés Laguna o Miguel Sabuco, todos los cuales han sido relativamente bien estudiados, tal como lo ha puesto de relieve Ivonne David-Peyre ${ }^{5}$.

Pues bien, en este artículo nos proponemos avanzar en el estudio de la metáfora cotejando su presencia en la obra de tres médicos de corte representativos del periodo. Con el objeto de profundizar en el conocimiento de las variables que intervienen en el desarrollo del tópico, además de documentar su presencia, nos planteamos como propósito particular la elucidación de las transforma-

3. MARAVALL, J.A. Estudios de historia..., p. 99.

4. DELPECH, F. "Marques corporelles et symbolique trifoncionelle: exemples ibériques". Le corps comme métaphore dans I'Espagne des XVI et XVII siècle. Du corps Métaphorique aux métaphores corporelles. A. Redondo. París 1992, pp. 93103.

5. DAVID PEYRE, I. "La alegoría del cuerpo humano en la península ibérica del Siglo de Oro". Archivo Iberoamericano de Historia de la Medicina 28 (1976), pp. 243254. 
ciones que sufrió la metáfora mediante el análisis y la comparación de sus respectivas formulaciones: en primer lugar, la formulación que aparece en la Segunda parte del Libro de la Anathomía del hombre de Bernardino Montaña de Monserrate $(1551)^{6}$; en segundo lugar, la que desarrolla Jerónimo Merola en la Primera parte de la República original sacada del cuerpo humano $(1587)^{7}$ y, finalmente, la que elabora Cristóbal Pérez de Herrera en la Introducción del Remedios para el bien de la salud del cuerpo de la república (1610)․ Las tres suficientemente separadas entre sí temporalmente, pero todas en un contexto lo bastante próximo como para permitir establecer algunas claves de cambio.

Valga decir que, tanto desde el punto de vista del material historiográfico como desde el punto de vista filológico y literario, se trata de tres obras de distinta envergadura y propósito, de distinta extensión e intención, pero las tres son coincidentes en el uso metafórico del cuerpo como dispositivo legitimador del poder: más o menos explícitamente, la intencionalidad política está resuelta y deliberadamente presente en las tres formulaciones. Y, en todo caso, se trata de tres obras compuestas por tres médicos de corte, en un lapso de casi sesenta años, cada una de las cuales en un reinado diferente -el de Carlos I, el de Felipe II y el de Felipe III- por lo que en conjunto conforman una expresión documental de extraordinario valor para el propósito planteado.

\section{Los textos y sus autores}

\subsection{El Libro de la Anathomía del hombre (LAH)}

El $L A H$ de Bernardino Montaña de Monserrate fue publicado en la ciudad de Valladolid en 1551. Aunque contiene abundantes reflexiones a propósito del comportamiento humano, de acuerdo con la tradición hipocrática, es formalmente y por su contenido un compendio anatomofisiológico cuyo propósito principal es la descripción de la estructura y las funciones del cuerpo humano. Aunque no se trata de una obra original en sentido estricto, presenta suficientes elementos formales y de contenido novedosos que le confieren gran relevancia literaria ${ }^{9}$. En

6. MONTAÑA DE MONSERRATE, Bernardino. El Libro de la Anathomía del hombre. Valla dolid: Casa de Sebastián Martínez, 1551. Ejemplar R 3398: Biblioteca Nacional de España. Trascripción BETA CNUM 7965.

7. MEROLA, Jerónimo. República Original sacada del cuerpo humano. Barcelona, Casa de Pedro Malo, 1587. Ejemplar 61001 M62 h y R: Biblioteca Nacional de España. Reproducción en rústica del ejemplar R/5914.

8. PÉREZ DE HERRERA, Cristóbal. Remedios para el bien de la salud del cuerpo de la República. Madrid. 1610. Ejemplar VC/1136/4: Biblioteca Nacional de España. Reproducción en rús tica del ejemplar R/28762(4).

9. VICENTE, M. "Saber médico e ideología en el «Libro de la Anathomía del hombre» de Bernardino Montaña de Monserrate. Tradición y modernidad en la alegoría onírica del cuerpo social". Bulletin of Hispanic Studies 86.5 (2009), pp. 593607. 
cualquier caso, se trata del primer tratado de anatomía escrito en lengua castellana, como destacaron Saunders y $\mathrm{O}^{\prime} \mathrm{Malley}^{10}$, lo que, indudablemente, hace de él una obra suficientemente representativa en la historia de la literatura médica.

Por lo que se refiere al empleo de la metáfora corporal, en el $L A H$ aparecen algunos de elementos del amplio espectro alegórico que desde la antigüedad ha ofrecido la analogía entre la sociedad y la figura humana para desarrollar, sobre la imagen de la armonía orgánica, una teoría política orientada a legitimar el orden establecido. Aunque la estructura que utiliza como modelo anatómico no es ni la república ni la ciudad sino una fortaleza, la descripción de los gremios, sus oficios y sus funciones, contiene, al calor de la mentalidad renacentista, los ingredientes básicos de las utopías urbanas del momento.

La obra, que en lo médico es una amalgama de conocimientos anatómicos y fisiológicos galénicos -aunque con pretensiones mecanicistas-, consta de dos partes y un coloquio entre el médico y su paciente. La primera parte es una detallada descripción anatómica a través de doce capítulos en cincuenta y ocho folios (recto y verso); la segunda, con tan solo dos capítulos dedicados a la generación, nacimiento y muerte del hombre, sirve de introducción al coloquio; en sí mismo, un tratado de fisiología humana de cincuenta y cuatro folios (recto y verso) en el que se pueden encontrar abundantes recomendaciones morales relacionadas con el buen gobierno corporal.

Precisamente, es en dicho coloquio donde Bernardino Montaña desarrolla su pensamiento organicista. Lo hace a través de la narración de un sueño alegórico que Luis Hurtado de Mendoza, Marqués de Mondéjar, confía a su médico -el propio autor- con el propósito de que este le dé cuenta de las figuras e imágenes que, con muy gran misterio, en el dicho sueño se le paresció: la magnífica arquitectura de una casa pulida y graciosa en cuyo interior ve construir una fortaleza.

En realidad, muy poco es lo que el médico ha de descubrir: la casa pulida es una mujer encinta y la fortaleza que el marqués ve construir en su interior con los materiales que hauia menester para la obra no es otra cosa que el feto en proceso de gestación. El propio autor, y por si quedara alguna duda al lector, va revelando la correspondencia de las imágenes arquitectónicas de la casa y de la fortaleza en construcción con las distintas regiones, órganos y sustancias anatómicas de la mujer y de su vástago en curso.

El relato del marqués comienza precisamente con la enumeración de las estructuras propias del proceso generativo y sus funciones:

10. SAUNDERS, J.B. DE C.M. y O'MALLEY, C.D. "Bernardino Montana de Monserrate: Autor of the first anatomy in the Spanish Language; its relationship to Mondeville, Vicary, Vesa lius, the English geminus, and the history of circulation". Journal of the History of Medicine and allied Sciences 1 (1946), pp. 87107. 
De tres quartos principales que esta casa tenia [...] en el quarto mas baxo y mas desechado de la casa hauia vna pieza por la qual salian cada mes fuera de la casa todas las obras del mantenimiento de los que viuian en ella.

Escolio. Esta pieça es la madre de la muger donde se engendra la criatura, por la qual sale cada mes la sangre que le sobra quando no esta preñada.

[...] andaua dentro de ella a el lado derecho un architector, el qual segun que sus obras dieron testimonio hera muy diligente ingenioso de gran entendimiento.

Escolio. El maestro es figura del espiritu genitivo.

Trataua de hazer alli vna fortaleza admirable [...]

Escolio. La fortaleza es figura de vn niño varon que se engendra en la madre.

[...] la primera cosa que hizo fue traer de la casa real una parte de los materiales que hauia menester para la obra.

Escolio. Los materiales son figura de la sangre venal y arterial de (al) [la] muger, de la qual con la simiente del varon se forma la criatura y se hazen las partes.

De los quales materiales hizo vna boueda cerrada por todas partes excepto un agujerillo [... ${ }^{11}$.

Una vez concluido el relato de la generación, la narración retoma la descripción del resto de las estructuras corporales a partir de la figura del embrión:

[el maestro] Traço primeramente tres quartos que hauia de tener la fortaleza, y señalo a cada vno de ellos su propio lugar y assiento.

Escolio. Los tres quartos son figura de la cabeça del pecho y del vientre.

En el quarto de enmedio que hera el mas principal de toda la fortaleza hizo el maestro vna estufa, de la qual salia vn caño grande [...]

Escolio. Esta estufa es el coraçon de donde sale el arteria grande mediante la qual se comunica el calor natural a todos los miembros.

En esta estufa [...] el mismo maestro [...] en adelante se hizo repostero mayor de lumbre $[\ldots]$

Escolio. Este repostero es el espiritu vital [...]

[...] hizo cabe la estufa el maestro vn ventalle muy galano de quatro pieças, con el qual ciertos pajes le ha-zian siempre ayre [...]

Este ventalle es figura de los liuia(u)[n] os los quales incessantemen-te trahen ayre fresco al coraçon y los pajes son los musculos que siruen para ello ${ }^{12}$.

11. MONTAÑA DE MONSERRATE, Bernardino. El Libro de la Anathomía..., fol. 83r y v.

12. MONTAÑA DE MONSERRATE, Bernardino. El Libro de la Anathomía..., fol. 83v. 
Y sucesivamente, donde un zaguán es la boca; una flauta es la garganta que emite sonidos; los pajes son los músculos del pecho; los mozos, músculos que mueven las piezas de la nuez; fuentecillas en el muro, las mamas; la cocina de la casa, el estómago; la puerta de la cocina, la boca del estómago; treintaidós mozos de cocina son dientes y muelas; un maestro de sala es la lengua; porteros que abren y cierran puertecillas cuando es preciso son los músculos de la boca; un aparador de cobre en el que se vuelve a cocer el alimento para hacer "quatro potajes" es el hígado donde se generan los cuatro humores; un cuarto superior es la cabeza sobre cuyas tres librerías, los ventrículos cerebrales, se encuentra el gobernador de la fortaleza, el espíritu animal, rodeado, según explica al detaIle, de tres maneras de ventanas: los ojos, la nariz y los oídos; etc.

Una de las cosas que primero Ilaman la atención en Bernardino Montaña es, por comparación con la mayoría de las versiones anteriores de la metáfora, la exhaustividad y minuciosidad descriptiva no tanto de los órganos corporales como de los enseres y habitantes de la casa. Parece evidente, a este respecto, que al interés didáctico que el autor manifiesta por la materia médica en los primeros compases de la obra, se une, al menos con la misma intensidad, un interés epistemológico: la demostración de la racionalidad de todo lo creado a través de una exposición argumentativa, simple pero insistente, cuyo mayor baluarte es la consignación de la ordenada y armónica concordancia de la realidad en todos sus planos. Justamente, el carácter que le otorga la revelación cuasi visionaria del sueño coadyuva, junto con la dignidad aristocrática de quien lo sueña, al proceso de legitimación tanto de los saberes que expone como del modelo social que trata de justificar.

Pero, tanto el modelo científico como el modelo social a los que se refiere Montaña están en decadencia.

Por una parte, su modelo anatómico sigue siendo galénico. Indudablemente Montaña conocía el De humani corporis fabrica de Vesalio publicado nueve años antes, y de él toma buena parte de la terminología e, incluso, algunas de sus láminas; sin embargo, su armazón conceptual continúa siendo el de la vieja medicina. Montaña no consigue desprenderse ni de la teoría humoral, ni de los principios de causación y finalismo aristotélicos ni, mucho menos, de la simbología de las tres cavidades galénicas (natural, espiritual y animal). En este sentido, se podría calificar la obra de Montaña como sólo superficialmente moderna: se aplica a armonizar las nociones de la medicina galénica y la propia noción de cuerpo en las estructuras del naciente pensamiento mecanicista. A este respecto, parece importarle más que el resultado final ofrezca una dinámica perfectamente armónica que la precisión descriptiva de los órganos y su fisiología.

Por lo que se refiere al modelo social, Montaña se inscribe en un patrón cuya coherencia es fundamentalmente jerárquica. Como la propia concepción anatómica que le da legitimidad, dicha coherencia y relación armónica está atenta sobre todo a las relaciones de dependencia paulatinamente decrecientes y, asi- 
mismo, a la distinción de las funciones de mando y de obediencia de los diferentes estamentos y gremios sometidos, en todo caso, a los principios de unidad y solidaridad orgánica de una sociedad que empezaba a dar signos de cambio.

No es, no cabe duda, el sueño de Bernardino Montaña, un sueño deliberadamente político; tampoco la arquitectura anatómica que pergeña a lo largo de la interpretación subsiguiente se configura abiertamente como un tratado en el que lo político se haga presente de manera reiterativa; sin embargo, bastan algunos pequeños pero determinantes párrafos estratégicamente traídos a colación por el autor a propósito del libre albedrío, la finalidad de la inteligencia práctica o los instrumentos de los que se sirven los espíritus animales, para que no quepa duda de la correspondencia que trata de establecer entre el orden natural, el orden moral y, por extensión, el orden político:

[...] porque considerando su fabrica de tanto primor y excelencia, y tanta proporcion como sus partes tenian entre si, y con todo el cuerpo no se podia pensar que aquella casa pudiesse ser hecha si no para aposento de alguna alma que tuuiesse excelencia sobre las otras almas porque como dize el principe a ver asi la vida y la perfecion y todo bien distribuye lo el criador segun la dispusicion del sujecto a quien lo da, porque en la tal distribucion no es nada parcial antes da a cada vno segun su merescimiento, por manera que en el cuerpo compuesto por gran primor y destreça y sabiduria no se puede pensar sino que ha de posar en el forma de grandissima perfecion ${ }^{13}$.

Pero la alegoría política en cuestión no parece limitarse a legitimar el orden político sino que participa, además, del sentido que en pleno siglo XVI empezaban a tener las denominadas utopías urbanas, como denominaba Eugenio Garín (1975) a las ilusiones ciudadanas de corte organicista. Como ha apuntado Barona (9), los reformadores humanistas podían encontrar en el cuerpo humano el modelo de estructura, a la vez racional y natural, construida a la medida de la naturaleza humana, sobre el que reformar la ciudad medieval, aglomeración humana y carente de todo orden.

\subsection{La República Original sacada del cuerpo humano (RO)}

La $R O$ única obra conocida de Jerónimo Merola -catedrático en la Universidad de Barcelona- se puede considerar como un tratado sociológico y filomédico con abundantes reflexiones sobre moral pública y conducta así como de ideas políticas de inspiración platónica. Publicado en Barcelona en 1587, se compone de un prólogo de cinco folios (recto y verso) y dos partes de 185 y 134 folios res-

13. MONTAÑA DE MONSERRATE, Bernardino. El Libro de la Anathomía..., fol. 87v. 
pectivamente (recto y verso), además de la presentación y una dedicatoria versificada al Sereníssimo Príncipe Don Carlos Emanuel Philiberto, Duque de Saboya.

No se trata de una obra de referencia ni en la historia de la medicina ni en los anales de las ideas políticas tal vez porque para ninguno de esos campos constituyó un sustancial avance; tampoco en el estilo resulta ser una obra original. No obstante, la envergadura del tratado, la profusión de pasajes alegóricos y, desde luego, la presencia de algunas figuras alegóricas notables, hacen de ella algo más que un simple episodio en la historia de los usos metafóricos del cuerpo. En todo caso, constituye una expresión genuina del desarrollo del organicismo político en las letras castellanas $^{14}$ donde los rasgos de la medicina mecanicista se hacen patentes.

Aparte del propio título, donde ya está insinuada la alegoría, el empleo del cuerpo como metáfora aparece en la misma dedicatoria del tratado. En ella Merola compara al Rey con el corazón en un sentido asistencial no muy habitual: "Y assí tiene al coraçón dentro del cuerpo, como Rey en mitad de su Reyno, para de allí socorrer a las partes necessitadas y menesterossas"15.

En el prólogo, que ocupa un total de cinco folios, además de las pertinentes justificaciones y explicaciones de las circunstancias en las que el autor emprende la obra, destaca la metáfora que establece entre el cuerpo y, primero con un terroncillo que hay que desmenuzar para encontrar lo que se desea, después con un libro que hay que leer con atención y, finalmente, en un notable alarde de inspiración, con las Indias: [...] qué indias tan grandes son las de nuestro cuerpo, quan sabiamente regidas, qué trabazón tan eslabonada, qué correspondencia y vecindad ${ }^{16}$.

La primera referencia al organicismo propiamente dicho, se da precisamente aquí mediante la invocación a la República de Platón:

Y viendo que había partes principales que gouernauan y mandauan, y partezillas de poco tomo que estas baxo dela disciplinade aquellas, y otras medianas, y que esta mesma traça se vehia en la ciudad, acordeme también de lo de Platón: Ciuitas bene instituta similis est fabrice corporis humani ${ }^{17}$.

Una invocación tamizada, como veremos, por el aún vigente uso medieval de la metáfora aunque no llega a mencionar a ninguna fuente medieval ni tampoco a ninguno de sus predecesores inmediatos en el empleo de la alegoría.

14. REDONDO, Augustin. "La métaphore du corps de la République à travers de le traité du médecin Jerónimo Merola (1587)". A. REDONDO. Le corps comme métaphore dans I'Es pagne des XVI et XVII siècles. París 1992, pp. 4153.

15. MEROLA, Jerónimo. República Original..., fol. a4.

16. MEROLA, Jerónimo. República Original..., Prólogo.

17. MEROLA, Jerónimo. República Original..., Prólogo. 
Que la intención de Merola es política, no cabe duda, pues el propósito explícito es hacer entender a los lectores:

[...] de dónde ayan nacido los estados tan diferentes de la República, y la orden que en ella ay. Por qué causa se da a unos más honra que a los otros [...] Para que vean el admirable concierto que hay en la ciudad bien instituyda [...] y que no trata solamente de la salud [...] sino que haze entender que la república tiene su disposición como la de nuestro cuerpo y es gouernada como como este mesmo cuerpo $^{18}$.

Si el cuerpo y la república tienen la misma disposición y es al médico a quien naturalmente corresponde el cuidado de la salud del primero, a él corresponde también interpretar la analogía entre ambos términos:

[...] pues a él le compite, como de suyo, entender y inquirir, el fundamento desta analogía y correspondencia que ay entre la ciudad que tienes todas sus partes y esta armazón y opificio admirable del hombre [...] Es el humano cuerpo, una recopilación y suma del mundo, causa final de todas sus cosas, retrato de la policía Real, de la dicha Aristocracia, quando buenos y sabios rige la cosa pública no se escapa la Economía, antes bien la naturaleza es el dechado de un perfectíssimo y solícito Ecónomo ${ }^{19}$.

La idea de solidaridad orgánica y unidad aplicada al cuerpo social aparece bien pronto, teñida de consideraciones morales y admoniciones dirigidas a los ociosos y pusilánimes; dirigidas a aquéllos que dedicándose exclusivamente a la contemplación -según señala- buscan el bien propio y no reparan en que la felicidad de la República consiste, según términos que recuerdan a los de Juan $\operatorname{Costa}^{20}$, en la vida de acción:

[...] acción dirigida al bien del próximo [...] que assí como el cuerpo y el ánima son inseparables durante la vida, ni es possible hazer sus operaciones el ánima sin el cuerpo, ni biuir el cuerpo sin el ánima, ni más ni menos pueden separarse la vida activa y contemplativa en la República Christiana [...] Y esta [acción] es tanto de mayor merecimiento quanto resulta más en el bien de muchos: como son las acciones públicas, empleadas en el bien de muchos en vna ciudad, o de todos en un Reyno por un buen gouierno ${ }^{21}$;

una idea, la del bien común, de larga tradición en la tradición filosófica occidental, pero que en el ámbito médico-político de las letras hispanas apenas

18. MEROLA, Jerónimo. República Original..., I, 1 r 2 r.

19. MEROLA, Jerónimo. República Original..., I, 2v 3 r.

20. COSTA, Juan. El regidor o ciudadano. Salamanca, Casa de Antonio de Lorençana, 1578.

21. MEROLA, Jerónimo. República Original..., I, 7v 8r. 
había sido explicitado. En cualquier caso, Merola no pierde la oportunidad de recalcar la disimilitud de la contribución que a cada miembro del cuerpo físico o del cuerpo social le corresponde según el lugar que cada cual ocupa, a imitación del orden natural gobernado por Dios:

[...] y assí es necessaria cosa, que trabajemos todos en esta República, vnos mandando, otros obedeciendo, con fin no de nuestra honra, ni prouecho, sino del bien de todos los que están comprehendidos en aquella massa imitando al autor de todo bien, el qual todo cría, conserua y mejora [... ] Y porque el bien del ánima, muy gran parte consiste en acción para con el próximo, y República, a organizado Dios de manera este cuerpo, que fuesse proporcionado instrumento para essa acción felice y perfecta en la qual consiste buena parte de las virtudes morales ${ }^{22}$.

Cabe señalar a propósito de este pasaje que por primera vez Merola hace referencia a la alegoría macrocosmos-microcosmos, justamente con la intención de dar cuenta del orden universal sobre la base de las similitudes entre todo lo creado y que sirve a Merola para legitimar el orden terrenal de la República y con él, como ha señalado Truman ${ }^{23}$, cerrar el círculo con el que se justifica la finalidad del hombre en la tierra, volver a Dios de quien deriva:

Que el mundo pequeño que es el hombre, es final causa a la que se refiere el grande: y Dios es fin del grande y del pequeño. Porque lo que pretende el hombre es hazer una circulación y boluerse a Dios de quien tiene su origen, y esto mediante la virtud, con la cual viene a hazerse tan virtuoso, tan perfecto y semejante a Dios, que por la similitud es atrahído por el sumo bien ${ }^{24}$.

Una buena fracción de la primera parte se configura como un largo discurso moral de reminiscencia aristotélica en torno a la buena disposición de la naturaleza y, dentro de esta, la del cuerpo, gobernados por Dios, que servirá a Merola para justificar oportunamente la cerrada unidad y adecuación armónica -como en su caso hiciera Bernardino Montaña- de todas las partes de la República y de su gobierno:

Porque la prudencia escoge medios conuenientes, y los dispone con tal orden, y la templança haze que la manera del proceder sea con tal moderación, y la justicia que sea con tanta equidad y finalmente la fortaleza no permite que se tome de la plaça más de lo que conviene [...] Y adonde ay

22. MEROLA, Jerónimo. República Original..., I, 19v 21 r.

23. Truman, Ronald W. Spanish treatises on government, society and religion in the time of Philip II. Leiden: Brill, 1999, p. 200.

24. MEROLA, Jerónimo. República Original..., I, 20v. 
todo esto es impossible que pueda auer falta ni cosa superflua [...] Esto se ve claramente en las partículas de nuestro cuerpo, por la anatomía ${ }^{25}$.

Una vez establecidas las premisas básicas de congruencia de todas las cosas -de las que el cuerpo es ejemplo-, el discurso se centra en la organización social del estado ideal cuyos oficiales supremos son, según dice, el teólogo (piloto del alma), el médico (piloto del cuerpo) y el letrado (piloto de los bienes) cuyas facultades -animal, vital y natural- han de estar en comunicación:

Siguiendo la traça de nuestro cuerpo, en el qual [...] las partes dichas príncipes, son auidas por muy honradas, y de gran preeminencia, porque tienen la acción del mando y gouiernos de todas las demás ${ }^{26}$.

Tras una larga defensa de la utilidad de la ciencia médica a la República, uno de los momentos más espléndidos de la obra, en cuanto al uso alegórico del cuerpo, se encuentra en el capítulo XXI y siguientes sobre la representación de las artes en el cuerpo. En ellos, mediante un bastante apócrifo razonamiento es capaz de establecer una triple escala analógica entre los bienes de la república (de fortuna, el alimento y la doctrina), las partes principales del cuerpo (hígado, corazón y cerebro) y las ciencias o artes para el regimiento de la ciudad (facultad civil, medicina y teología):

Cuanto más me voy metiendo en las cosas de nuestro cuerpo, y por sus pasos voy midiendo las de la República, más a las veras me voy marauiIlando de ver lo mucho que se parecen. La Analogía de más calidad [...] es la que ay entre los bienes de la República y en el cuerpo se pretenden, y las artes que estos bienes tratan. Los bienes de fortuna [...] que son el alimento con que los ciudadanos se mantienen a ellos se parecen la sangre y el espíritu natural (si puede admitirse que tal espiritu aya) pues desta sangre se sustentan los ciudadanos del cuerpo y por la misma razón será el Hígado la cifra y biua figura de la facultad Civil, que estos bienes dispensa y distribuye. Desta sangre el coraçón viene a nodrecerse y labrar su sangre arterial y vital el espíritu, con lo cual viene a dar aliento y vida a todo el cuerpo: de suerte que la vida tiene su assiento en el coraçón. Y como esta vida la trate el Médico no será disparata cosa ayuntar como en casamiento a nuestra medicina con el coraçón [...] se entiende, y es muy manifiesto, que está cifrada y figurada la Theología en el cerebro pues ella es la que envía sus rayos de doctrina por todos los miembros de la República ${ }^{27}$.

25. MEROLA, Jerónimo. República Original..., I, 33v 34v.

26. MEROLA, Jerónimo. República Original..., I, 60r.

27. MEROLA, Jerónimo. República Original..., I, 100v 102v. 
Un razonamiento trufado de galenismo -aunque con poco convencimiento como se desprende la duda expresada sobre la existencia del espíritu animal$y$, asimismo, de doctrina paulina que desemboca en la legitimación de la medicina y del médico para deliberar sobre los asuntos del Estado.

Precisamente, es la doctrina paulina a propósito del cuerpo místico, de tan larga tradición en la letras hispánicas ${ }^{28}$ la que sirve a Merola para dar un paso más en la representación del poder y poner de relieve de manera expresa el orden de los estados, hombres que goviernan y no son governados, los que goviernan y son governados y los que lo mismo que en el cuerpo solo son governados, en aras de la unidad y mutuo beneficio, a imitación de una naturaleza cuya más excelsa muestra es el cuerpo el cuerpo humano; una naturaleza a la que hay que regresar, al decir de Merola, de acuerdo con la aseveración "Ars imitatur naturam inquantum potest" ${ }^{\prime 29}$ que le sitúa más allá de lo medieval. Porque, no es sólo que la República, que es artificial, pueda ser comparada con el cuerpo; Merola sostiene que si la República se organiza según la naturaleza será natural de manera que los medios (médicos) de curación del organismo serán, por analogía, de aplicación a la conservación y asiento del Estado.

\subsection{El Remedio para el bien de la salud del cuerpo de la república (RBS)}

De los tres autores cuyas obras sometemos el estudio, Cristóbal Pérez de Herrera es sin duda el más notorio de todos. Lo es por el estatus que llegó a ostentar (protomédico de galeras) y, asimismo, por la amplitud y trascendencia social y política de su producción literaria. Bien conocido por obras como el Amparo de pobres y otras composiciones destinadas a la transformación del paisaje urbano de su tiempo, merecería figurar, según Fraile ${ }^{30}$ o Cavillac ${ }^{31}$, entre los urbanistas y economistas precursores de la moderna ciencia política. En todo caso, se trata de un decidido reformador social que, a diferencia de dos los anteriores, llegaría a elaborar un buen número de propuestas prácticas de índole tanto arquitectónica como urbanística, económica, de administración y control social, de salubridad e higiene, de organización de la práctica asistencial, etc.

Siendo médico, como lo eran Montaña y Merola, su obra está repleta de consideraciones relativas a diversas cuestiones médicas, no exentas de recomendaciones morales de acuerdo con la tradición galénica de la que tampoco

28. MARAVALL, J.A. Estudios de historia...

29. MEROLA, Jerónimo. República Original..., I, 171v.

30. FRAILE, Pedro. "Administrar la ciudad y gobernar a los individuos: Pérez de Herrera y los antecedentes de la Ciencia de Policía", en J. M. BEASCOECHEA, La ciudad contemporánea, espacio y sociedad, Universidad del País Vasco, Bilbao 2006, pp. 351372.

31. CAVILLAC, Michel. "El Madrid utópico (1597 1600) de Cristóbal Pérez de Herrera" Bulletin hispanique 104.2 (2002), pp. 627644. 
él supo desprenderse. Sin embargo, lo que en los dos autores precedentes pudiera ser considerado como un signo de conservadurismo epistemológico no lo es tanto en Pérez de Herrera dado que su obra, y particularmente el $R B S$, no pertenece al ámbito de la ciencia o la teoría médica propiamente dichas sino, de manera más decidida y declarada que las obras de sus predecesores, al de las ideas políticas. En ella, la alegoría, construida en buena parte sobre la metáfora salud/orden y prosperidad frente a enfermedad/desorden y pobreza, alcanza su más genuina expresión política en tanto que estrategia discursiva reformista en torno al bien común; es decir, ligada al ideal el renacentista de ciudad económicamente dinámica, hacendosa, limpia de inmundicias y, sobre todo, moralmente ordenada, libre de "mendigantes" ociosos y demás "pícaros", siempre conforme a la católica razón de Estado.

Aunque puede reconocerse la metáfora en diversos pasajes de su amplia obra, en la mayor parte de los casos se manifiesta de manera esporádica y parcial a excepción del escrito que traemos a colación, el $R B S$, un discurso que Cristóbal Pérez de Herrera dirige a Felipe III en 1610, cuya introducción está formada íntegramente por la mencionada alegoría organicista. El propósito del discurso es informar al rey de las penurias por las que atraviesa el Estado a la vez que trata de persuadirle para el emprendimiento de las reformas que, a su juicio, evitarían la quiebra económica; propósito en cuyo contexto cobra sentido la comparación de la acción política con el ejercicio de la medicina.

En total, el discurso tiene 32 folios (recto y verso) de los que tres son una presentación y los seis siguientes la susodicha introducción. Formalmente, la alegoría que está sustentada en el uso clásico del organicismo, tiene un carácter didáctico; le sirve al autor para ilustrar la explicación de las medidas políticas que luego defenderá en el cuerpo del discurso:

Hame parecido, Señor, para la introducción de lo que en este papel propusiere, seguir en algo una alegoría en los términos de mi facultad, con que se explicara más apazible y cómodamente el intento y concepto de lo que se dirá, haziendo comparación de la República al cuerpo humano, no siendo muy fuera de propósito esta analogía y correspondencia, pues los antiguos Filósofos le llamaron microcosmos, que significa mundo pequeño: porque su armonía y compostura admirable corresponde mucho a él: por ser el humano cuerpo en su cierta definición, una recopilación y suma del mundo, causa final de todas sus cosas, y aun retrato de la lerarquía y orden del cielo ${ }^{32}$.

32. PÉREZ DE HERRERA, Cristóbal. Remedios para el bien de la salud..., 4r. 
Como ya advirtió David-Peyre ${ }^{33}$, en Pérez de Herrera el manejo de la alegoría aparece invertido. Frente a la consideración más común según la cual esta sirve para apuntalar el estado de cosas bajo la imagen de completitud y armonía orgánica que ofrece el cuerpo cuando goza de salud -tales son los casos de Montaña y de Merola-, aquí la utopía se construye, como declaración de la intencionalidad reformista, a partir de la comparación de la España de su tiempo con un cuerpo enfermo, enflaquecido, necesitado de grandes remedios.

Aclarado que la cabeza es el monarca, aun estando este en plenitud, no puede gobernar la República si todos los órganos encargados de su sustento padecen algún desorden. Pérez de Herrera exonera así a Felipe III de la responsabilidad de los males que aquejan al Estado depositándola, sucesivamente, en los distintos estamentos, cada uno de los cuales con su correspondencia orgánica. En primer lugar, los estamentos inferiores: los labradores, los ganaderos, los oficiales, los mercaderes, etc. los cuales, no obstante, adquieren el protagonismo que la fisiología galénica había dado al hígado en tanto que órgano encargado de producir y distribuir la sangre. Ésta, cuando es poca y de mala calidad, dice, enferma el cuerpo. De igual modo acontece la descomposición del Estado:

[...] por auer dexado todos estos sus antiguas costumbres, y codicia loable de trabajar y sustentarse de mantenimientos de poca costa [...] que han dexado muchos sus casas, e ídose a mendigar por España, con gran daño della [...] Y desto nace, que auiendo de embiar el hígado (como lo hace en el cuerpo humano) la sangre bastante para sustentar la cabeça y coraçón, y las demás partes del cuerpo, embía poca, y de tan mala calidad, que se enflaquece todo, y haze notable falta, por tener la cabeça precisa necesidad de ser seruida y socorrida, como la parte principal deste cuerpo, adonde residen las potencias y sentidos, que le gobiernan, y miran por él: que no sin propiedades V. M. y su Real casa y familia, Ministros y Consejeros ${ }^{34}$.

No se libra la nobleza de la diatriba, aquí con una orientación de índole más económica. Quienes sustentan la República en autoridad tales como Grandes, Títulos, Caballeros y gente noble y rica, el estómago en la alegoría, son acusados por Pérez de Herrera de haber gastado incluso la mitad de lo que tienen de renta para demostrar su grandeza, a imitación unos de otros, hasta provocar el decaimiento del Estado entero que en el organismo obra como destemplanza:

33. DAVID PEYRE, Ivonne. "La alegoría del cuerpo humano en el prólogo al Memorial de Cristóbal Pérez de Herrera (1610)". Actas del Quinto Congreso Internacional de Hispanistas 1. F. López, J. Pérez, N. Salomon y M. Chevalier. Burdeos, Instituto de Estudios Ibéricos e Iberoa mericanos, 1977, pp. 311317, p. 312.

34. PÉREZ DE HERRERA, Cristóbal. Remedios para el bien de la salud..., 4v 5r. 
[...] que no puede hazer la digestión, y cozer como conuiene, con que se engendran muchas crudezas. Y haciendo por esta causa mal quilo, que los Médicos llamamos, que es la sustancia de los alimentos que se comen, de que se haze (lleuada al hígado del estómago) la massa sanguinaria de los cuatro humores en él, para sustentar todo el cuerpo no lo puede hazer como conuiene, por auerlos empobrezido y ayudado a perder, en lugar de socorrerlos y ampararlos sus mismos dueños a los vassallos, metiéndolos en fianças, y apurándoles sus caudales con sus gastos excesiuos, que todo es causa también de la fría y poca sangre que dezimos reparte el mismo hígado a la cabeça y coraçón, y a todo el cuerpo ${ }^{35}$.

Uno de los pasajes más singulares de la alegoría lo constituye la referencia la escasez de gentes motivada, entre otras cosas, por la reciente expulsión de los moriscos, que Pérez de Herrera ejemplifica con las sangrías y purgas que en la época llevaban a cabo los médicos, para ayudar al cuerpo a expeler los malos humores, antes de proceder a su restablecimiento:

Y Aunque con esta tan gran euacuación que se ha hecho a este cuerpo de la República, causada de la expulsión tan necessaria y acertada desta gente que ha salido fuera destos Reynos, aurá quien piense, auerse enflaquezido y disminuydo las fuerças della, como lo hazen los malos humores que se sacaron por sangrías y purgas del cuerpo humano, pues con todos juntos, buenos y malos passaua, antes que se començasse la cura, y obligasse la enfermedad a ello: y después de sacados, procuramos rehazerlos, y conualecer con sustancias, pistos y otros alimentos a propósito, para boluerle a su antiguo vigor ${ }^{36}$.

No pierde la ocasión, como se ve, a pesar del carácter recriminatorio del discurso, de honrar la figura del monarca aprobando la que a todas luces, fue una aciaga medida no solo social sino también económica.

De todos modos, y para apresurar al monarca a emprender las acciones necesarias, la figura no podía ser sino médica. La idea de la enfermedad y su necesaria cura, además de incontestable en su simplicidad, le permite cerrar el círculo argumentativo que daba satisfacción a la profesión médica: a saber, la importancia de obrar con premura en la aplicación de los remedios:

Para curación deste cuerpo tan grande de la República, ay precisa necesidad de acudir con presteza, siguiendo un precepto de Hipócrates, que dize, Que la ocasión se desliza y es apresurada, por lo qual es bien no perderla: y haziéndolo assi, con el ayuda de nuestro Señor, tiene muy cierta

35. PÉREZ DE HERRERA, Cristóbal. Remedios para el bien de la salud..., $6 \mathrm{r} 7 \mathrm{v}$.

36. PÉREZ DE HERRERA, Cristóbal. Remedios para el bien de la salud..., 7r. 
la próspera salud: y tomándose de ueras y con resolución, començando por los remedios contrarios a la enfermedad, como enseña la Medicina y sus preceptos, será muy cierta: y mucho más se certifica, por ser España tan fértil y abundante de todo lo que ha menester la vida humana [...] que reformándose, y desempeñándose, será muy fácil boluer en sí, y ser riquíssimos, teniendo V.M. entre ellos muchos vassallos, Grandes, Títulos, y Caualleros, dueños de muchos lugares y villas como se espera [...] que todo da a entender la grandeza increyble de España y su riqueza inaccesible, y mucho más boluiendo en sí, como se espera ${ }^{37}$.

Con todo, el modelo político de Cristóbal Pérez de Herrera no se separa en lo sustancial del tópico renacentista de la metáfora corporal; recoge los elementos básicos del organicismo clásico y medieval y los adapta al interés político de carácter reformista que le mueve. A este respecto, se puede decir que frente a la mayoría de los usos de la época -desde luego frente al uso que hicieran Montaña y Merola-, el foco de la metáfora no está situado sobre la relación de dependencia orgánica de los distintos estamentos y gremios que dan sustento al estado en tanto que unidad; el interés principal de Pérez de Herrera no es sancionar el carácter unitario y armónico de la República, sino convencer de los remedios que permitieran aliviar su menoscabo. La idea de unidad orgánica surge inevitablemente en un aparente segundo plano de la lectura sobre todo si, de dicha lectura, se extraen los elementos que de coyuntura económico-política contiene. En este plano, Pérez de Herrera se decanta inequívocamente por la monarquía como modelo político ideal y, con ella, por los principios de jerarquía y dependencia -tal vez antes que de interdependencia- como instrumento al servicio del bien común. En esto, también la recurrente segunda epístola paulina a los Corintios, en su llamada a la solidaridad orgánica, constituye un punto de reconfortante apoyo para quienes el reparto social no obtuvieron sino posiciones subalternas.

Pero, aunque sea pertinente extraer dichos elementos de contexto para situar el uso del tópico en la serie histórica y de pensamiento en los que se enmarca la Introducción del $R B S$, son justamente tales elementos lo que le confieren singularidad en dicha serie. Es lo que sitúa dicha Introducción en un plano distinto al de sus antecesores; un plano mucho más próximo a las ideas políticas de la modernidad.

\section{Síntesis comparativa}

\subsection{Tipo de documento según su composición, temática e intención}

Como hemos apuntado, los tres textos fueron escritos por médicos de corte aunque, de los tres, sólo el primero, el Libro de la Anathomía del hombre, puede

37. PÉREZ DE HERRERA, Cristóbal. Remedios para el bien de la salud..., 8r 9r. 
ser considerado como un tratado cuya materia es de índole médico propiamente dicho; la metáfora organicista aparece formalmente en él como una digresión al servicio de la comprensión de dicha materia, es decir, con carácter didáctico.

La República original es, en su conjunto, un tratado de teoría sociológica y política: su Primera parte, la que contiene la metáfora organicista, si bien cuenta con abundante léxico médico y argumentación organológica, no constituye por su objeto un tratado de medicina propiamente dicho. Lo mismo puede decirse de la Segunda parte, cuyo propósito es ilustrar sobre el origen de la medicina legal. Aunque la intención del autor es también didáctica, en este caso no con relación al saber médico sino con relación a la acción política.

Finalmente, la Introducción al Remedio para el bien de la salud del cuerpo de la república pertenece al género de los memoriales; un género a través del que sus autores hacían llegar al monarca informes o propuestas de actuación económica, política, social, etc. Aunque la metáfora corporal aparece en diversos pasajes de la obra, es en la Introducción a la misma donde la alegoría alcanza su máxima expresión y su más decidido carácter médico. Aquí, la intención es, antes que didáctica, propedéutica; funciona como ejemplo que antecede y prepara el discurso subsiguiente destinado a persuadir al monarca sobre asuntos de política económica.

\subsection{Modelo de legitimación}

Los tres escritos constituyen un inequívoco refrendo de las estructuras del poder; si bien todos se ajustan a la concepción organicista del Estado, hay algunas diferencias en los modelos que proponen.

La legitimación del poder aparece representada en el LAH por la adhesión incondicional y casi sumisión del médico a su paciente Marqués quien parece poseer por revelación onírica las claves del orden social que tan bien representa la armonía del cuerpo humano y tan minuciosamente interpreta y sanciona el médico. Médico que está al servicio de su paciente, el Marqués de Mondéjar; al servicio del cuerpo humano y su buen funcionamiento; $y$, en última instancia, al servicio del orden social establecido representado, en este caso, por un edificio bien construido y bien administrado. En todo caso, se trata de un modelo de legitimación en positivo; es decir, en la afirmación del estado de cosas (descrito mediante una utopía) como mejor condición de lo real.

El modelo de legitimación de la $R O$ esta expresado también en positivo. No obstante, el refrendo del statu quo sobre la imagen del cuerpo humano es más genérico: aunque está referido a la república cristiana, utiliza términos, asociaciones y analogías muy imprecisas referidas al orden universal o el orden de la naturaleza, de acuerdo con la tradición clásica. A este respecto, la centralidad que otorga a la ciencia médica en la conservación del orden de la República -así como en el cuerpo humano lo es el corazón- pone de relieve que la defen- 
sa de la medicina está al menos en el mismo plano que la defensa del orden social establecido.

El texto que en este aspecto presenta mayor singularidad de los tres, es sin duda, la RBS. Aun cuando el autor no vacila en dar carta de naturaleza a las relaciones sociales jerárquicas sobre imagen del cuerpo en sana armonía, el modelo de legitimación es aquí planteado en negativo, es decir, a partir de la descripción de la quiebra de un Estado sobre el que es preciso intervenir como el médico lo hace ante el organismo enfermo. Pero es que Pérez de Herrera no es un tratadista teórico; es, como hemos apuntado, un reformador que se dirige a su monarca crudamente para convencerle del emprendimiento de medidas económicas y sociales prácticas.

\subsection{Forma y sentido}

Por lo que se refiere a la forma y el sentido en el que es construida la metáfora hay notables diferencias entre los tres escritos.

El $L A H$ se presenta en forma de coloquio, como parte aclaratoria de un amplio compendio anatomofisiológico. Dicho coloquio, antes que un debate renacentista, se configura como un diálogo típicamente medieval, simple en su forma, plano en lo dialéctico, sin discusiones ni refutaciones importantes, donde las preguntas y las respuestas son previsibles porque lo que importa al autor es, más bien que el estilo, o la argumentación, mostrar lo más claramente posible su visión -más bien estática- de la realidad. Aparte del uso del coloquio como estrategia didáctica, lo más destacable en cuanto a la forma es el sentido inverso en que está presentada la metáfora; aunque sin comprometer en absoluto las funciones ideológicas de la misma, Bernardino Montaña no utiliza la imagen del cuerpo para representar el orden social -en este caso a través del orden arquitectónico y funcional de una casa bien construida- sino que es la imagen de la casa la que le sirve para representar la "maravillosa" composición del cuerpo humano.

Por su parte, tanto la $R O$, como la $R B S$ mantienen el modelo clásico directo: la analogía según la cual el objeto representado es la república y la ciudad respectivamente y el cuerpo humano aparece como significante si bien, como ya hemos apuntado, de modo bien distinto en cada uno de ellos: más genéricamente en el caso de la obra de Merola -un tratado al estilo convencional con reminiscencias clásicas y paulinas- y de forma muy concreta y expeditiva en el escrito de Pérez de Herrera -parte de un Memorial con intenciones reformistas-.

\subsection{La metáfora organicista en su contexto}

Estamos ante tres escritos cuyos autores comparten una misma profesión, la médica, y parecidas convicciones sobre la legitimidad del saber médico. Aunque los tres comparten los principios teóricos de la medicina galénica, sólo el 
LAH presenta cuestiones de carácter epistemológico sobre la validez de dicho conocimiento indicando el tránsito hacia la medicina moderna representada en ese momento por el mecanicismo. La $R O$, por su parte, participa de dicho modelo bien encarnado en la idea de la "fábrica corporal" de Vesalio, que Merola trata de aplicar al orden de la República aunque, como ya puso de relieve Redondo ${ }^{38}$ hace dos décadas, sin Ilegar a mencionarlo.

La $R B S$, pese a ser posterior, no posee signos mecanicistas; algo que se puede interpretar como fruto de los intereses más políticos que médicos propiamente dichos.

Los tres autores pertenecen a una misma tradición cultural, con parecidos alineamientos e intereses ideológicos, aunque con expresión distinta, matizados por las circunstancias y la condición de cada uno ellos: en particular, sus respectivas posiciones sociales pero, también, las vicisitudes y el tiempo en el que escribe cada uno de ellos (los reinados de Carlos I, Felipe II y Felipe III, respectivamente). En todo caso, tienen unas preocupaciones semejantes en torno a la política y el modelo de orden social: organicismo vertical, jerárquico y, a la vez, centralizado. Preocupaciones para las que el cuerpo humano, médicamente percibido, continuaba siendo la mejor de las representaciones. Atendiendo al modelo clásico, una representación en la que gobernar equivalía a preservar la salud y reformar, a curar.

Tanto Bernardino Montaña como Jerónimo Merola y Pérez de Herrera, pertenecen al Siglo de Oro español. Aunque los tres están insertos en la corriente de pensamiento humanista, son apreciables diferencias con respecto a la incorporación o no de ideas modernas en el uso metafórico del cuerpo. Bernardino Montaña parece situarse justo antes de la frontera de la modernidad; Merola, a pesar de confeccionar una metáfora con reminiscencias clásicas, incorpora elementos que permiten detectar la transición a la modernidad. Por su parte, Pérez de Herrera, con un discurso casi más económico que político, práctico, concreto, se muestra como el más moderno de los tres. En ambos, frente al discurso de Montaña, aparece expresada la defensa del bien común como objeto final del orden orgánico del Estado.

38. REDONDO, Augustin. La métaphore du corps..., p. 44. 